\title{
Reorientação do estágio de Odontologia no SUS subsidiada pela criticidade de preceptores
}

Cristina Berger Fadel*; Eduardo Bauml Campagnoli*; Marcos Cezar Pomini**; Karine Leticia da Silva***; Alessandra de Souza Martins****

\author{
* Doutor(a), Professor(a) Adjunto, Departamento de \\ Odontologia, Universidade Estadual de Ponta Grossa \\ ** Mestrando em Clínica Odontológica, Faculdade de \\ Odontologia de Piracicaba \\ *** Mestranda em Odontologia, Universidade Estadual de Ponta \\ Grossa \\ **** Doutora, Professora Colaboradora, Departamento de \\ Odontologia, Universidade Estadual de Ponta Grossa
}

Recebido em 13/09/2018. Aprovado em 22/12/2019.

\begin{abstract}
RESUMO
O preceptor de estágio exerce influência chave na formação profissional e pessoal do estagiário. Uma vez que o preceptor está grande período de tempo em contato com o acadêmico, este pode auxiliar na identificação das principais limitações do estágio curricular de Odontologia no Sistema Único de Saúde (SUS). O objetivo deste estudo foi expor percepções críticas de cirurgiões-dentistas preceptores de estágio no SUS, com enfoque no processo de reestruturação curricular de um curso de graduação em Odontologia. Realizou-se pesquisa exploratória e descritiva com abordagem qualitativa junto a cirurgiões-dentistas preceptores de estágio $(n=8)$ do referido curso. A apreensão das informações se deu por meio da técnica em entrevista de Grupo Focal e os dados foram transcritos e categorizados por meio da Análise de Conteúdo Temática. Da análise emergiram quatro dimensões: Estrutura Organizacional, Perfil do Estagiário, Serviço de Saúde e Atuação do Orientador. Os preceptores investigados assumem a importância do estágio para a integração entre academia e serviço. Todavia, sua percepção encontra-se arraigada no modelo biologicista, o que sugere um enorme desafio às políticas públicas atuais e em especial à mudança curricular do curso de Odontologia, centrada na integralidade da atenção humana e na abordagem humanista, crítica e reflexiva em saúde.
\end{abstract}

Descritores: Preceptoria. Educação Superior. Sistema Único de Saúde. 


\section{INTRODUÇÃO}

Os estágios supervisionados dentro da Estratégia Saúde da Família (ESF) oferecem aos acadêmicos da área de saúde uma vivência privilegiada da realidade social e epidemiológica na qual estão inseridos, estimulando as suas competências profissionais e qualificações para atuação no Sistema Único de Saúde (SUS). Referenciando aqui especificamente a formação em Odontologia, a inserção de alunos no SUS apresenta certas limitações, relacionadas principalmente à discrepância entre ensino e realidade brasileira, bem como à estruturação dos estágios e dos profissionais envolvidos ${ }^{1}$. Por estas razões, discussões políticas e acadêmicas tem sido constantes, com a finalidade de desenvolver políticas públicas e mudanças curriculares que propiciem uma qualificação do ensino e uma adequação do profissional frente às necessidades de saúde da população ${ }^{2}$.

Dada a relevância da integração entre ensino superior em saúde $\mathrm{e}$ as múltiplas realidades sociais brasileiras, considerando o direito do acesso universal à saúde, e principalmente o fato de que diversas Instituições de Ensino Superior (IES) não possuem em seus currículos de ensino disciplinas que enfatizem a formação profissional odontológica voltada à integralidade da atenção humana, o Conselho Nacional de Educação aprovou, em 2002, as Diretrizes Curriculares Nacionais (DCN), as quais exigiam das IES reformulações em seus Projetos Pedagógicos dos Cursos a fim de garantir uma melhor qualificação profissional, tornando os futuros cirurgiões-dentistas aptos a exercerem sua profissão de maneira integrada, universal e justa em qualquer contexto social ${ }^{3}$. Visando este processo de aproximação qualitativa entre academia e serviço, o Ministério da Saúde criou em 2005 o Programa Nacional de Reorientação da Formação Profissional em Saúde - Pró Saúde, e em 2010 o Programa de
Educação pelo Trabalho para a Saúde - PET Saúde, os quais se mostram essenciais para as consolidações das diretrizes curriculares e para que as práxis educativas e profissionais sejam enriquecidas e continuadas ${ }^{3}$.

Botti e Rego (2010) ${ }^{4}$ relataram a importância do preceptor na formação profissional e pessoal do estagiário. Segundo os autores, tais sujeitos contribuem com o planejamento e desenvolvimento do estágio, estímulo ao raciocínio crítico, controle e análise de desempenho, aconselhamento, observação e avaliação do estagiário, assim como com a formação moral do acadêmico. Neste sentido, estando o preceptor de estágio grande período de tempo em contato com o acadêmico, observando e instruindo suas ações, este pode auxiliar diretamente na compreensão e resolução dos principais problemas enfrentados e nas mudanças que se fazem necessárias para o aprimoramento do estágio no SUS, qualificação e formação profissional do acadêmico ${ }^{1,5}$. Atesta-se, então, que o preceptor possui uma responsabilidade chave no estreitamento da distância entre a teoria e a prática na formação dos estudantes de graduação em Odontologia ${ }^{6}$.

Por estas considerações e pela ciência de que o exposto deve endossar as modificações propostas pelas DCN, o objetivo deste estudo foi expor as percepções críticas de cirurgiõesdentistas preceptores sobre o estágio acadêmico na Estratégia Saúde da Família, com enfoque no processo de reestruturação curricular de um curso de Odontologia.

\section{METODOLOGIA}

O presente estudo obedeceu aos preceitos estabelecidos pela Resolução $n^{\circ} 466 / 12$ do Conselho Nacional de Saúde e obteve aprovação do Comitê de Ética em Pesquisa (parecer $\left.\mathrm{n}^{\circ} 1.821 .264 / 2016\right)$. O campo de investigação deste estudo foi o estágio curricular no SUS, no 
âmbito da atenção básica em saúde, do curso de Odontologia de uma universidade pública do sul do Brasil. Adotou-se o modelo de estudo exploratório descritivo, com abordagem qualitativa.

O curso em tela é constituído por duas vertentes disciplinares: uma direcionada à formação especifica profissional com um total de 3.655 horas, e as disciplinas de estágio curricular supervisionado com 1.037 horas. As disciplinas da base curricular do curso são distribuídas por matérias anuais e semestrais, com envolvimento integrado entre teoria e prática. De acordo com o arranjo de ensino, a área da Saúde Coletiva (SC) é subdividia em três momentos de aprendizagem: SC I, II e III. A disciplina de SCI atua principalmente no campo da etiologia e prevenção de doenças bucais; a SCII dentro dos preceitos da epidemiologia e políticas públicas de saúde, com caráter voltado à ciência e construção de ferramentas teóricas e metodológicas necessárias ao planejamento e administração de serviços públicos de saúde; e a SCIII, refere-se especificamente às práticas no Sistema Único de Saúde, por meio de estágio curricular obrigatório. O estágio em SCIII ocorre no oitavo período do curso, com carga horária de 51 horas, sendo a carga horária restante (986 horas) dividida entre as disciplinas de SC I e II.

Atualmente a disciplina de SCIII segue a lógica de um estágio semidireto de observação e ação. Um grupo de, em média seis acadêmicos, é vinculado a um Professor Orientador de Estágio e a um Preceptor, representado pelo cirurgiãodentista (CD) de uma Equipe de Saúde Bucal, em uma das Unidades de Saúde da Família do município de referência. Como método pedagógico, busca a integração entre o ensino da saúde e os serviços nas Unidades de Saúde da Família (USF), numa articulação entre o saber conviver, saber científico e popular almejando então uma experiência subjetiva e reflexiva de formação profissional.

$\mathrm{O}$ presente estudo apresentou como população alvo a totalidade de cirurgiõesdentistas preceptores de estágio na Estratégia Saúde da Família (ESF) de um curso de graduação em Odontologia $(n=11)$. Como critério de inclusão observou-se o período mínimo de três anos de atuação na preceptoria de estágio no SUS. O ano base para a consulta foi 2016. Os sujeitos foram previamente informados sobre os objetivos da pesquisa, seu caráter de voluntariedade e não identificação, assim como sobre a forma de coleta, análise e finalidade dos dados. Os que aquiesceram com sua participação, o fizeram, inicialmente mediante assinatura de um Termo de Consentimento Livre e Esclarecido. Do total de preceptores convidados para integrar o estudo $(n=11)$, houve recusa por parte de três deles.

Utilizou-se, para a apreensão das informações, a técnica de entrevista em Grupo Focal $^{7}$. Esta é uma modalidade científica da pesquisa qualitativa utilizada no entendimento das diferentes percepções e atitudes acerca de um fato, prática, produto ou serviço. A essência do grupo focal consiste na interação entre os participantes e o pesquisador, que objetiva colher dados a partir da discussão focada em tópicos específicos e diretivos. A condução desta etapa se deu por meio de um pesquisador treinado para coletar os dados, sem influenciar nas respostas. Utilizou-se de roteiro elaborado com questões provocadoras, construídas a partir de narrativas de docentes ligados ao objeto em tela e de pesquisa literária. Os sujeitos falaram livremente sobre todos os aspectos considerados contra produtivos para a efetivação do estágio curricular no SUS, sobre desencadeantes de desajustes no seu cotidiano de trabalho e sobre estratégias para a qualificação da relação entre universidade e serviço de saúde. Houve realização de estudo piloto com dois cirurgiões dentistas da atenção 
básica em saúde inseridos em processo de trabalho regido pelo modelo tradicional de atenção à saúde, não vinculados à Estratégia Saúde da Família.

A entrevista foi realizada em espaço neutro, externo às dependências institucionais e as unidades de saúde, visando à liberdade de expressão dos informantes. Esta fase teve duração de setenta minutos e foi gravada. Os resultados foram transcritos integralmente pelo pesquisador em documento Word (Microsoft Corp., Redmond, Washington, USA), analisados manualmente, categorizados por meio da técnica de Análise de Conteúdo Temática e discutidos com suporte de literatura científica.

\section{RESULTADOS}

Diante a análise das narrativas dos preceptores, emergiram quatro dimensões: Estrutura Organizacional, Perfil do Estagiário, Serviço de Saúde e Atuação do Orientador. Cada dimensão desmembrou-se em categorias e subcategorias apresentadas nos quadros 1 a 4.

Quadro 1. Descrição da dimensão 'Estrutura Organizacional' e categorias, identificadas nas narrativas de preceptores

\begin{tabular}{|c|c|c|}
\hline \multirow{5}{*}{ 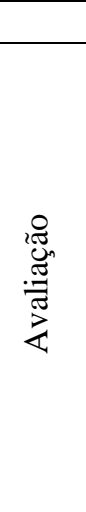 } & \multicolumn{2}{|r|}{ DIMENSÃO: ESTRUTURA ORGANIZACIONAL } \\
\hline & Carga Horária & $\begin{array}{l}\text { "Não são em } 8 \text { aulas que eu consigo avaliar se o meu acadêmico está realizando bem ou } \\
\text { mal a sua atividade." }\end{array}$ \\
\hline & $\begin{array}{l}\text { Influência do } \\
\text { Professor }\end{array}$ & $\begin{array}{l}\text { "A maneira como vem sendo realizada a avaliação não está de acordo. Eu já peguei turmas } \\
\text { muito ruins, e a Professora me disse para reprovar meus acadêmicos, mas não acho que esse } \\
\text { seja o ponto." }\end{array}$ \\
\hline & $\begin{array}{l}\text { Sentimento de } \\
\text { Incapacidade }\end{array}$ & $\begin{array}{l}\text { "Eu acho que os Professores passam uma responsabilidade pra nós. Eu que tenho que } \\
\text { reprovar ou não, porque sou eu que estou avaliando, mas não tenho capacidade pra aprovar } \\
\text { ou reprovar alguém." }\end{array}$ \\
\hline & Modelo de atuação & $\begin{array}{l}\text { "Eu não posso avaliar alguém que veio observar. Eu tenho que avaliar um aluno que veio } \\
\text { desenvolver determinada atividade. Se ele vem ao estágio observar uma área, observar o } \\
\text { funcionamento, como avaliá-lo?" }\end{array}$ \\
\hline \multirow{5}{*}{ 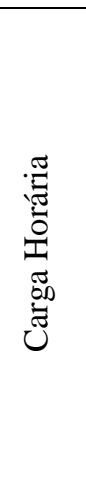 } & \multirow{5}{*}{ Insuficiente } & "A carga horária deles na unidade deveria ser de um período inteiro. (Ano)" \\
\hline & & $\begin{array}{l}\text { "Se eu tenho o estagiário quem sabe o ano todo, posso dividi-los de uma maneira mais } \\
\text { inteligente. Isso eu não tenho como fazer em oito aulas". }\end{array}$ \\
\hline & & $\begin{array}{l}\text { "Eu não tenho a capacidade de colocar na mente de um estagiário uma coisa que ele aprendeu } \\
\text { desde o começo do curso. Ele tinha que vivenciar isso, não só em oito aulas. Assim ele perde } \\
\text { o incentivo pelo serviço público." }\end{array}$ \\
\hline & & $\begin{array}{l}\text { "Eu creio que deveria ser em vários momentos. Eu não posso achar que o estagiário vai } \\
\text { aprender desde a parte burocrática, isso ele pode aprender perfeitamente no começo do curso. } \\
\text { A parte de territorialização é até bom que vejam antes, pois eles chegam lá no estágio e já tem } \\
\text { uma visão melhor". }\end{array}$ \\
\hline & & $\begin{array}{l}\text { "A carga horária dos acadêmicos é pequena. O estágio poderia ser realizado em diversos } \\
\text { dias." }\end{array}$ \\
\hline \multirow{4}{*}{ 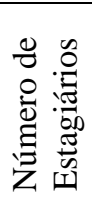 } & \multirow{4}{*}{ Saturação } & "Mas para o acadêmico atuar no consultório da USF, eu não posso colocar seis estagiários na \\
\hline & & mesma sala e no mesmo período. Para que haja respeito entre mim, paciente e acadêmico, \\
\hline & & $\begin{array}{l}\text { eu preciso de uma açao construtıva, onde ambos vao aprender." } \\
\text { "A quantidade de todos eles (acadêmicos) na minha sala é muito alta." }\end{array}$ \\
\hline & & "Se eles estivessem em dois, o controle situacional seria diferente." \\
\hline
\end{tabular}




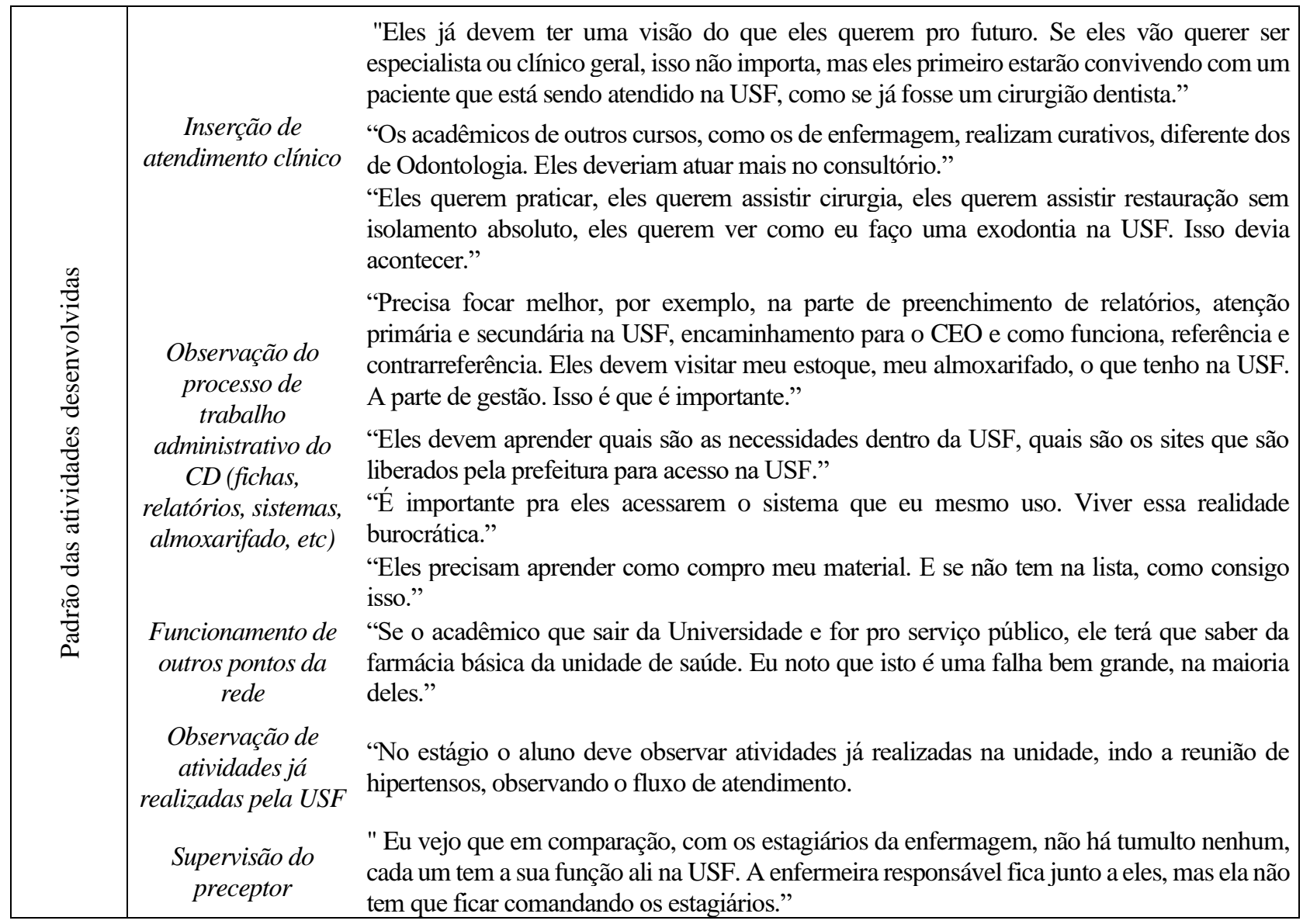

Quadro 2. Descrição da dimensão 'Perfil do Estagiário' e categorias, identificadas nas narrativas de preceptores

\begin{tabular}{|c|c|c|}
\hline \multicolumn{3}{|r|}{ DIMENSÃO: PERFIL DO ESTAGIÁRIO } \\
\hline $\begin{array}{c}\text { Ausência de } \\
\text { Interesse }\end{array}$ & Serviço Público & $\begin{array}{l}\text { "Os acadêmicos não têm vontade de trabalhar no SUS futuramente." } \\
\text { "Eu acho que o estágio deles ajuda desmotivar bastante eles para o serviço público." } \\
\text { "O acadêmico pensa que trabalho no SUS é muito pouco recompensado financeiramente e } \\
\text { a qualidade de trabalho e do material que é utilizado é inferior ao do serviço particular. AII } \\
\text { ele vê o profissional do SUS como aquele que realizou concurso porque não obteve sucesso } \\
\text { em consultório particular." } \\
\text { "Eles já vão para o estágio com essa idéia na cabeça, que veio só observar. Isso abre espaço } \\
\text { para conversa paralela. Ou então, me pedem que seja rápido porque querem ir pra outra } \\
\text { aula, ou estudar pra prova" } \\
\text { "Os acadêmicos não mostram interesse pelo trabalho." } \\
\text { "Hoje em dia enquanto estiverem liberando curso de pós graduação pra aluno, eles nunca } \\
\text { vão se interessar pelo serviço público." }\end{array}$ \\
\hline Despreparo & $\begin{array}{c}\text { Técnico } \\
\text { Profissional }\end{array}$ & $\begin{array}{l}\text { "Os acadêmicos já vêm mal preparados para o estágio. Às vezes não sabem nem fazer } \\
\text { levantamento no estilo CPO-D, um levantamento básico." } \\
\text { "As palestras que eles fazem, não chamam a atenção das crianças". } \\
\text { "Eles não tem preparo, então o problema é o período que estão fazendo o estágio." }\end{array}$ \\
\hline Comportamento & Pessoal & "Alguns acadêmicos não se comportam bem na USF." \\
\hline
\end{tabular}


Quadro 3. Descrição da dimensão 'Serviço de Saúde' e categorias, identificadas nas narrativas de preceptores

\begin{tabular}{|c|c|c|}
\hline \multicolumn{3}{|r|}{ DIMENSÃO: SERVIÇO DE SAÚDE } \\
\hline$\frac{\circ}{3}$ & Equipe de saúde & "As ACS não gostam de ajudar nas metas." \\
\hline$\stackrel{\Xi}{\lessgtr}$ & & "As ACS não gostam de sair a campo com os acadêmicos da Odontologia." \\
\hline 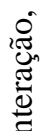 & & $\begin{array}{l}\text { "Eles vêm ao estágio com suas metas e preciso ir atrás dos colegas da unidade, das } \\
\text { agentes comunitárias, do médico, enfermeiro, farmacêutico e pedir para me ajudarem } \\
\text { cumprir essas metas e eles não gostam." }\end{array}$ \\
\hline 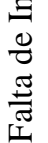 & Comunidade & $\begin{array}{l}\text { "Existem famílias que não gostam de receber os acadêmicos em suas casas. É difícil } \\
\text { conseguir uma família que aceite cinco estagiários, mais dentista, mais ACS." }\end{array}$ \\
\hline
\end{tabular}

Quadro 4. Descrição da dimensão 'Atuação do Orientador' e categorias, identificadas nas narrativas de preceptores

\begin{tabular}{|c|cc|}
\hline \multicolumn{3}{|c|}{ DIMENSÃO: ATUAÇÃO DO ORIENTADOR (PROFESSOR) } \\
\hline & Preceptor & "Não tenho preparo prévio para receber meus estagiários" \\
& $(C D)$ & $\begin{array}{l}\text { "Acho que deveria haver um método para que eu, Professor e acadêmicos pudéssemos } \\
\text { trabalhar juntos, para eu entender o que o Professor espera de mim." }\end{array}$ \\
& "Há um acordo entre a Universidade e a Prefeitura, mas não há acordo das partes \\
comigo e com meus colegas profissionais para receber os estagiários."
\end{tabular}

\section{DISCUSSÃO}

Os estágios curriculares nos serviços públicos de saúde são fruto da evolução de uma série de propostas de aproximação entre as instituições de ensino superior e o SUS, com trajetórias diferenciadas nos processos de articulação e integração para os diferentes cursos ${ }^{8}$. Nos cursos de Odontologia, as experiências extramuros no SUS buscam a vivência de situações reais junto à população, sendo a Estratégia Saúde da Família (ESF), local privilegiado de aprendizagem e formação de profissionais competentes e com espírito crítico ${ }^{8}$. Com base nas potencialidades dos estágios no SUS para a formação profissional, discutem-se aqui quatro dimensões consideradas determinantes da baixa produtividade do estágio, por parte de preceptores de Odontologia.

\section{A Estrutura Organizacional do Estágio}

Em relação ao padrão das atividades desenvolvidas no estágio, a Associação Brasileira de
Ensino Odontológico (2002) ${ }^{9}$ aponta que o futuro profissional deve desempenhar todas as atividades pertinentes a um profissional de saúde, incluindo práticas e políticas em saúde pública. Para o Ministério da Educação $(2002)^{10}$, os estágios curriculares para a formação em Odontologia deve abranger, de forma articulada, a formação generalista, humanista, crítica e reflexiva do futuro profissional em todos os níveis de atenção à saúde. E por fim, para o Conselho Federal em Odontologia $(2005)^{11}$ os estágios consistem em atividades de competência única e exclusiva das instituições de ensino, tal como a inserção do estágio no programa didático pedagógico da instituição.

Para os sujeitos dessa pesquisa, as atividades clínicas deveriam ocupar espaço privilegiado no estágio, uma vez que proporcionaria maior envolvimento e interesse dos estagiários, frente à aplicabilidade e aprimoramento de habilidades cirúrgico-restauradoras adquiridas durante a graduação. Esta visão hegemônica arraigada do 
papel do cirurgião-dentista na ESF pode estar relacionada à dificuldade de apreensão da dimensão social das práticas de saúde bucal; da limitação do conceito saúde/doença; da baixa incorporação das diretrizes do SUS em seus campos de trabalho e de um provável distanciamento da equipe de saúde; da forma como sua atuação ainda hoje é avaliada, sob base de produção em série de procedimentos clínicos.

Seguindo a lógica curativista exposta pelos preceptores, o número de estagiários passa a ser outro fator limitante da qualidade do estágio. Essa percepção desconsidera as práticas que vão além das atividades clínicas, como medidas educativas e promotoras de saúde, atenção domiciliar, trabalho em equipe multiprofissional, criação de vínculo com usuários, planejamento em saúde, acolhimento, escuta e comunicação ${ }^{12}$, além de desconsiderar a necessidade da abordagem integral do processo saúde e doença com ênfase na atenção básica ${ }^{13}$, e a importância de adquirir competências para a tomada de decisões, capacidade de liderança e de gestão em saúde ${ }^{8}$. Por outro lado, baseando-se no pressuposto de que o manejo e o controle de três ou menos estagiários é facilitado, em comparação a uma quantidade maior, de fato a quantidade de acadêmicos em uma única unidade poderia ter influência direta na qualidade do estágio.

Em relação à carga horária, os preceptores expõem ideias mais contemporâneas, ao considerarem que a participação continuada dos acadêmicos nos campos de estágio, com inserção em mais de um período semanal, teria desdobramentos positivos tanto na quebra de paradigmas sobre o serviço público, quanto na potencialização de suas vivências e de seu processo de trabalho na USF. Nesse sentido, estudos relatam que uma carga horária maior de estágio possibilitaria também maior aproximação qualitativa do preceptor ao acadêmico, e que esse contato estimularia o ato de pensar e a construção de novas hipóteses, além de permitir a descoberta da importância do trabalho coletivo por parte do aluno ${ }^{5}$.

De fato uma carga horária curricular escassa, como a de quatro horas semanais, em regra, impossibilitaria o estabelecimento de vínculos sólidos entre acadêmicos, comunidade e equipe de saúde. Ainda, seria entrave para o reconhecimento de aspectos burocráticos, como a alimentação de prontuários, relatórios e encaminhamentos. A literatura tem relatado que o alcance dos objetivos do estágio, assim como a integração de ensino e serviço no SUS estão diretamente relacionados à aproximação temporal continuada dos envolvidos ${ }^{14}$. Estágios de curta duração representam menor grau de envolvimento com a rotina dos serviços, sendo, muitas vezes, a obrigatoriedade da disciplina e a avaliação a única motivação do acadêmico ${ }^{15}$. Nesse sentido, acentua-se que o estágio deve potencializar a visão crítica-reflexiva do acadêmico, potencializando propostas de humanização e cuidado $^{16}$.

$\mathrm{Na}$ categoria avaliação do estágio, a carga horária reduzida é novamente percebida como fator limitante, juntamente com o sentimento de incapacidade normativa e situacional. O tema avaliação é sempre instigador pelos sentimentos que produz, seja no aluno, seja no professor ou nos preceptores ${ }^{15}$. Masetto e Prado (2004) ${ }^{17}$ identificam os seguintes sentimentos em relação a esse processo: tensão, medo, insegurança, arbitrariedade, injustiças, poder, controle, objetividade e subjetividade. Além disso, situações de constrangimento no momento de 'dar a nota' e a falta de preparo para avaliar os estagiários são igualmente mostradas pela literatura $^{12}$. Como a avaliação deve ser desenvolvida durante e não somente no término das atividades, através de critérios claros, caracterizando-se como uma oportunidade para a melhoria e não apenas como um instrumento de controle sobre $\mathrm{o}$ realizado $^{5,12}$, as questões apontadas pelos preceptores poderiam ser minimizadas, potencializando o aprendizado e o diálogo entre preceptor e estagiário. 


\section{O perfil do estagiário}

Dentre as características esperadas para um estagiário no SUS, a ausência de interesse foi a principal questão apontada pelos preceptores pesquisados. Estudos demonstram que a impassibilidade acadêmica pode estar relacionada à falta de estímulo e confiança na relação preceptorestagiário, a um sentimento de insegurança, a mídia e a própria formação superior ${ }^{18-20}$. Epstein e Carlini $(2012)^{18}$ demonstram que a insegurança e a falta de apoio por parte de acadêmicos criam um ambiente de ansiedade e exclusão do papel ativo do estagiário, fazendo com que este apresente um sentimento de desmotivação para com o estágio e o serviço público. Deve-se considerar ainda que, para muitos acadêmicos, o estágio em unidades de saúde é o primeiro contato com profissionais de fora do ambiente universitário, motivo que pode ser fator predisponente para ansiedade, nervosismo e insegurança $^{19}$.

Grande et al. $(2016)^{20}$ vinculam o desinteresse de acadêmicos pelo trabalho no sistema público de saúde, em parte, como resultante do desabono do SUS pelos meios de comunicação social. Associado a isso, os autores classificam que a formação acadêmica odontológica curativista, tecnicista, biologicista e individualista gera um distanciamento prático dos princípios e metodologias de trabalho do SUS, a qual, novamente, pode resultar em desmotivação pelo trabalho neste sistema. No entanto, estas premissas não podem suprimir a necessidade de estagiários atuarem sob bases sólidas de preparo técnico, científico, humano e reflexivo.

O despreparo de acadêmicos para o estágio no SUS é outra consideração apreendida por preceptores no presente estudo; e esta questão tem sido frequente não somente na Odontologia, mas também em outras categorias profissionais da saúde $^{21}$. Duas explicações podem estar atreladas a este fato: a primeira é que a realidade do funcionamento do sistema de saúde público brasileiro difere dos ensinamentos de sala de aula, especialmente devido à diversidade étnico-social brasileira e a arraigada abordagem educacional conteudista $^{20,22}$; e a segunda, refere-se à falta de comprometimento e dedicação pessoal de alguns alunos $^{21}$. Ambos os fatores podem ser minimizados pelo fortalecimento das relações interpessoais no processo de trabalho, envolvendo acadêmicos, Preceptores e Professores, e também, por meio de práticas pedagógicas conformadas na mediação com o outro. Estudos têm demonstrado que em campos de estágio onde o aluno é acolhido, ouvido, respeitado e incluído de forma participativa nas atividades de funcionamento da unidade, existe maior interesse por parte dos acadêmicos ${ }^{19,23}$. Ainda, que o preceptor de estágio deve ter uma abordagem de ensino em saúde para com o acadêmico capaz de instigar o seu raciocínio crítico, a comunicação, a discussão e elaboração de atividades clínicas e a participação no funcionamento do serviço de saúde, incentivando assim a prática reflexiva e ativa dos estudantes durante o estágio ${ }^{23}$.

\section{Serviço de saúde}

$\mathrm{Na}$ opinião dos preceptores o principal limitante no que se refere a características do serviço de saúde é a interação dos estagiários com os membros da equipe de saúde, em especial com os agentes comunitários de saúde (ACS). A resistência de categorias de profissionais da saúde quanto ao desenvolvimento do estágio tem sido amplamente debatida, e tem-se sugerido que esta fragilidade deva ser combatida com o estabelecimento de vínculo, a fim de criar uma parceria com ACS e outros profissionais, demonstrando que a participação de acadêmicos nos serviços de saúde traz benefícios para a comunidade local e é fundamental no cumprimento de metas dos ministérios da saúde e educação ${ }^{24}$. De fato alguns profissionais podem estar acomodados no modelo de trabalho medicalizante do passado, apresentando resistência ao trabalho multiprofissional. Contudo, as modificações dos currículos propostas pelos 
ministérios da educação e saúde, devem acentuar a formação multiprofissional, facilitando a sua execução prática.

Já a resistência por parte das famílias, no que tange ao acolhimento de acadêmicos em seus domicílios, pode estar relacionada quantitativamente ao desconforto causado pelo número elevado de indivíduos em um mesmo espaço físico particular, ou qualitativamente, pela falta de aproximação com os acadêmicos e de compreensão da importância dos mesmos vivenciarem diferentes realidades sociais e de saúde para a sua formação profissional. Toassi, Davoglio e Lemos $(2012)^{19}$ demonstraram que com o desenrolar das atividades e o número crescente de visitas, as famílias da área de contingência do estágio passam a aceitar a equipe de estágio cada vez melhor, e ainda, a desenvolver elos afetivos. De fato, a facilitação do acesso, o acolhimento e a criação de vínculo com as famílias têm sido demarcados como importantes características da abordagem integralista de atenção proposta pelo SUS ${ }^{13}$.

\section{Atuação do orientador}

$\mathrm{Na}$ dimensão atuação do orientador, as percepções concentraram-se na qualidade da comunicação. O planejamento anterior à inserção do estagiário nas unidades, a atuação conjunta e participativa com o orientador do estágio, e a ciência e aderência à pactuação entre universidade e serviço de saúde foram relatados.

De fato, a falta de conhecimento do que se espera do relacionamento preceptor-estagiário, tem sido demonstrada como uma limitação no desenvolvimento do estágio, e amplamente discutida na literatura ${ }^{12,23}$. Bispo, Tavares e Tomaz $(2014)^{6}$ demonstraram que preceptores, principalmente devido à sua formação acadêmica biologicista, sentem necessidade de realizar aperfeiçoamentos que possam melhorar o serviço de saúde e colaborar de forma mais eficaz na formação dos acadêmicos. Os autores sugerem ainda a inserção de um processo de educação continuada entre os preceptores e as IES, a qual possa garantir o desenvolvimento de uma capacidade didáticopedagógica mais adequada de preceptores, focada na atuação interdisciplinar. Da mesma maneira, Warmling et al. (2011) ${ }^{1}$ classificam como um desafio para o SUS progredir nas discussões que possam esclarecer sobre o papel, as atribuições e as institucionalizações do preceptor e do tutor.

\section{CONCLUSÕES}

A apreensão das percepções de sujeitos envolvidos em disciplinas de estágio acadêmico no SUS traz benefícios que repercutem diretamente na formação profissional, na comunidade e no serviço de saúde, pois instiga o aprimoramento de abordagens em saúde pública, que visem à transformação de práticas voltadas à promoção e qualificação do cuidado. Diante das atuais diretrizes curriculares e das mudanças estruturais dos cursos de Odontologia, o estágio no SUS, como parte essencial da formação profissional, exige do acadêmico uma abordagem centrada na ação integral, humanista e multiprofissional, sendo a Estratégia Saúde da Família campo fértil.

Os cirurgiões-dentistas preceptores aqui investigados consideram o estágio como potencializador das ações em saúde e fundamental na integração entre academia e serviço. Contudo, sua percepção formadora ainda encontra-se centrada no modelo biologicista, o que pode ter acentuado as críticas voltadas principalmente à dificuldade da inserção acadêmica nos diferentes espaços sociais, à ausência do manejo clínico durante o estágio, ao desinteresse e despreparo do acadêmico e à carga horária insuficiente. Estes apontamentos sugerem um enorme desafio frente às políticas de saúde e de educação superior governamentais (especialmente no que tange à mudança curricular do curso de Odontologia pesquisado), uma vez que estas estão fundamentadas em pilares centrais voltados à abordagem integral, humanística e multiprofissional 
em saúde.

\section{ABSTRACT \\ Reorientation of the Dentistry internship in the SUS based on the criticality of preceptors}

Dental preceptors have a key influence on trainees' professional and personal development. Because the preceptor spends a great deal of time in contact with the student, they can help in identifying the main limitations of the curricular internship in the Unified Health System (SUS). The aim of this study was to disclose critical perceptions of dental preceptors in the SUS, focusing on the curricular change of an undergraduate dentistry program. An exploratory, descriptive and qualitative study was carried out with all preceptors $(n=8)$ of this dentistry program. The information was gathered through a focus group interview, and the data were transcribed and categorized using thematic analysis. From the analysis, four dimensions emerged: Organizational Structure, Student Profile, Health Service and Performance of the Mentor Teacher. The preceptors investigated assume the importance of the internship for the integration between academia and service. However, their perceptions are rooted in the biologicist model, which suggests a huge challenge to current public policies and, in particular, to the curricular change in dentistry programs, centered on the integrality of human attention and a humanist, critical and reflexive approach in health.

Descriptors: Preceptorship. Education, Higher. Unified Health System.

\section{REFERÊNCIAS}

1. Warmling CM, Rossoni E, Hugo FN, Toassi RFC, Lemos VA, Slavutzki SMB, et al. Estágios curriculares no SUS: experiências da Faculdade de Odontologia da UFRGS. Rev ABENO.2011;11(2):63-70.

2. Dias HS, Lima LD, Teixeira M. A trajetória da política nacional de reorientação da formação profissional em saúde no SUS. Ciênc Saúde Coletiva. 2013;18(6):1613-24.
3. Moimaz SAS, Wakayama B, Garbin AJI, Garbin CAS, Saliba NA. Análise situacional do estágio curricular supervisionado nos cursos de graduação em Odontologia no Brasil: uma questão de interpretação. Rev ABENO. 2016;16(4):19-28.

4. Botti SHO, Rego S. Processo ensinoaprendizagem na residência médica. Rev BrasEduc Med. 2010;34(1):132-40.

5. Barreto VHL, Monteiro ROS, Magalhães GSG, Almeida RCC, Souza LN. Papel do Preceptor da Atenção Primária em Saúde na Formação da Graduação e Pós-Graduação da Universidade Federal de Pernambuco - um Termo de Referência. Rev Bras Educ Med. 2011;35(4):578-83.

6. Bispo EPF, Tavares CHF, Tomaz JMT. Interdisciplinaridade no ensino em saúde: o olhar no preceptor na saúde da família. Interface (Botucatu). 2014;18(49):337-50.

7. Merton RK, Fisk M, Kendall PL. (1956) The Focused Interview. A Manual of Problems and Procedures. Glencoe, IL: Free Press.

8. Werneck MAF, Senna MIB, Drumond MM, Lucas SD. Nem tudo é estágio: contribuições para o debate. Ciênc saúde coletiva. 2010;15(1):221-31.

9. Associação Brasileira de Ensino Odontológico. Diretrizes da ABENO para a definição do estágio supervisionado nos cursos de Odontologia. Rev ABENO. 2002;2(1):39.

10. Ministério da Educação (Brasil). Resolução CNE/CES 3, de 19 de fevereiro de 2002. Institui Diretrizes Curriculares Nacionais do Curso de Graduação em Odontologia. Diário Oficial da União 4 mar 2002; Seção 1.

11. Conselho Federal de Odontologia (Brasil). Resolução CFO-63/2005. Aprova a Consolidação das Normas para Procedimentos nos Conselhos de Odontologia. Diário Oficial da União 19 abr 2005; Seção 1. 
12. Rocha PF, Warmling C, Toassi R, Preceptoria como modalidade de ensino na saúde: atuação e características do preceptor cirurgiãodentista da atenção primária. Rev Saberes Plurais - Educação na Saúde. 2016; 1(1):96102.

13. Schimith MD, Lima MADS. Acolhimento e vínculo em uma equipe do Programa Saúde da Família. Cad Saude Publica. 2004;20(6):1487-94.

14. Neco HVPC, Oliveira FD, Florêncio E, Moreira AR, Valério CONS, Santos PR, Samary EGB, Antunes MBC. A integração ensino-serviço na qualificação da atenção básica. Rev Ciênc Med Pernamb. 2011;7(3):36-50.

15. Sousa DP, Nunes MF. Percepção dos Preceptores Cirurgiões-dentistas sobre as Diretrizes Curriculares Nacionais. Atas CIAQ2014. 2014;2(1):40-5.

16. Casate JC, Correa AK. A humanização do cuidado na formação dos profissionais de saúde nos cursos de graduação. Rev Esc Enferm. 2012;46(1):219-2.

17. Masetto MT, Prado, AS. Processo de avaliação da aprendizagem em curso de Odontologia. Rev ABENO. 2004;4(1):48-56.

18. Epstein I, Carlin K. Ethical concerns in the student/preceptor relationship: a need for change. Nurse Educ Today. 2012;32(8):897902.

19. Toassi RFC, Davoglio RS, Lemos VMA. Integração Ensino-Serviço-Comunidade: o Estágio na atenção básica da graduação em Odontologia. Educ Rev. 2012; 28(4):223-42.

20. Grande IMP, Prochnow R, Saab R, Pizzatto E. Desafios na formação do Cirurgião-Dentista para o SUS. Rev ABENO. 2016;16(3):2-6.
21. Dias BVB, Almeida JR, Maia JPP. Avaliação no estágio: percepções dos alunos de um curso de Enfermagem do interior do estado de São Paulo. REAS. 2016;8(3):913-19.

22. Finkler M, Caetano JC, Ramos FRS. Integração "ensino-serviço" no processo de mudança na formação profissional em Odontologia. Interface (Botucatu). 2011;15(39)-1053-70.

23. Luz GW, Toassi RFC. Percepções sobre o preceptor cirurgião-dentista da Atenção Primária à Saúde no ensino da Odontologia. Rev ABENO. 2016;16(1):2-12.

24. Santos KT, Ferreira L, Batista RJ, Bitencourt KTF, Araújo RP, Carvalho RB. Percepção discente sobre a influência de estágio extramuros na formação acadêmica odontológica. Rev Odontol UNESP. 2013;42(6):420-5.

\section{Correspondência para:}

Marcos Pomini

e-mail: marcospomini@outlook.com

Departamento de Prótese e Periodontia

Faculdade de Odontologia de Piracicaba

UNICAMP

Avenida Limeira, 901, Areião

13414-903 Piracicaba/SP 